\title{
NATURAL SELECTION IN WAR
}

\author{
Conclusions as to Eugenic Results of Conflict Cannot Be Drawn Without Inquiry \\ As to Very Large Number of Different Factors-War May Either \\ Help or Hinder Race Betterment-Present Strife is \\ Overwhelmingly Dysgenic in Effect
}

\author{
Roswell H. Johnson \\ University of Pittsburgh, Pittsburgh, $P a$.
}

\section{T}

HE unqualified statement that war is either eugenic or dysgenic in its effect on the human race, is found, on closer investigation to be unjustifiable. The modification of selection by war is far more manifold than the literature on the biological effects of war would lead the reader to suppose. All wars are partly eugenic and partly dysgenic. Some are mainly eugenic and others mainly dysgenic.

Natural selection should be subdivided into (1) lethal, that which operates through differential mortality; (2) sexual, that which operates through differential mating; and (3) fecundal, that which operates through differential fecundity. Again, selection operates both in an inter-group competition and an intra-group competition. We must, then, in analyzing the influence of any agency on natural selection, examine it under each of these six heads. In the case of war, however, we may eliminate fecundal selection, as it is little influenced. Still another division arises from the fact that the action of selection is different during a war upon the armed forces themselves and upon the population at home; and after the war, upon the nations with the various modifications that the war has left.

We will consider lethal selection first. To measure the effect of the inter-group selection of the armed forces, we have to compare the relative quality of the two races involved. The evidence for believing in substantial differences between races is based $(a)$ upon their relative achievement when each is isolated, (b) upon the relative rank when the two are competing in one society, and 546 (c) upon the relative number of original contributions to civilization each has made. Such comparisons lead us to reject the sentimental equalitarianism that denies race differences. While we admit of course a great deal of overlapping, there are, nevertheless, real average differences. To think otherwise is to discard evolution and revert to the older standpoint of "special creation."

The comparison of the quality of the two sides becomes more and more difficult as fighting is more and more between groups of allies which may differ greatly among themselves. Yet this by no means removes the inequality of the two sides taken each as a whole.

Without entering into the evidence at this time, we readily see that the eugenic effect of war would be very different according as the sides differ much or little. Yet this difference in quality, however great, will have no significance, unless the superior or inferior side is in general more likely to lose fewer men. Where the difference has been considerable, as between a civilized and savage nation, it has been seldom that the superior does not triumph with fewer losses. Victory, however, is influenced much less in these later days by the relative military efficiency of two single nations than by the success in making alliances with powerful nations. But such alignments are by no means always associated with better quality, because (a) there is a natural tendency for the weak to unite against a strong nation, $(b)$ to side with a group which is apparently succeeding, and $(c)$ the alliances may be the work 
of one or a few individuals who happen to be in positions of power at the critical time.

\section{HIGH QUALITY ON BOTH SIDES}

In this present war the contrast is particularly noticeable, since on both sides the combatants are in so large a proportion members of the old Teutonic or Hebrew races, both stocks being preëminent for their contributions to science and art. In this very feature, it is probable that we have the most noteworthy dysgenic element in the present war.

As for the selection taking place within each of the struggling nations, we must consider first of all the contrast between the combatants and the noncombatants of the same age and sex. This difference depends largely on how the army in question was raised. Where the army is a permanent, paid force, it probably does not represent a quality above the average of the nation, except physically. When it is conscripted, it will be superior physically, and probably slightly in other respects. If it is a volunteer army, its quality will depend largely on whether the cause being fought for is one that appeals to adventurers merely or one that appeals to some moral principle. In the latter case, the quality may be such that the loss of a large part of the atmy will be peculiarly damaging. This situation is more common than might be supposed, for by skillful diplomacy and journalism, a cause which may be really questionable, is presented to the public in a most idealistic light. In the present war, the soldiers of each country have been made to believe that they are the glorious defenders against unprincipled aggressors.

Even within the army of one side, lethal selection is operative. Those who are killed are by no means a haphazard sample of the whole army. Among the victims there is a disproportionate representation of those with (1) dauntless bravery, (2) recklessness, (3) stupidity. These qualities merge into each other, yet in their extremes they are widely different. However, as the nature of warfare changes, with the increase of artillery, mines and bombs, and decrease of personal combat, those who fall are more and more chance victims:

In addition to the killed and mortally wounded, there are many deaths from disease or from wounds which are not necessarily fatal. Probably the most selective of any of these three agencies is the variable resistance to disease and the widely varying knowledge and appreciation of the need for hygienic living shown by the individual, as, for instance, less reckless drinking of unsterilized water. But here, too, in modern warfare, this item is becoming less selective, with the advance in discipline and in organized sanitation.

The efficiency of selection will be affected by the percentage that each side has sent to the front, if the combatants are either above or below the average of the population. A nation that sends all its able-bodied males forward will be affected differently from its enemy that has needed to call upon only one-half of its able-bodied men in order to win its cause.

\section{THE POPULATION AT HOME}

Back from the fighting lines of the contending sides, the conditions that prevail are rendered more severe in many ways than in times of peace. Poverty becomes rife, and sanitation and medical treatment are commonly sacrificed under the strain. During a war, that mitigation of the action of natural selection, so common now among civilized nations, is somewhat less effective than in times of peace.

After a war has been concluded, certain new agencies of inter-group selection arise. The result depends largely on whether the vanquished have had a superior culture brought to them, as in the case of the Philippines, or whether, on the contrary, certain diseases have been introduced or crushing tribute has been levied, as in the Franco-Prussian War, or grievous oppression such as befell the Hebrews in Egypt.

Sometimes the conquerors themselves have suffered severely as the result of 
excessive spoliation, which has produced vicious idleness and luxurious indulgence, with the ultimate effect of diminishing the birth rate.

Within the nation there may be various results. Sometimes, by the reduction of overcrowding, natural selection will be less severe. On the other hand, the loss of that part of the population which is more economically productive is a very serious loss, leading to excessive poverty with increased severity in the action of natural selection. Selection is also rendered more intense by the heavy burden of taxation, as is now so evident in Great Britain directly, and in the very common depreciation of currency as in the Southern States after the Civil War.

Sexual selection as well as lethal is affected by war in manifold ways. Considering the armed force, there is an inter-group selection, when the enemy's women are assaulted by the soldiers. While this has been an important factor in the past, this is less common now, with better army discipline and higher social ideals.

Within the group, mating at the outset of a war is greatly increased by many hurried marriages. There is also sometimes an increase of illegitimacy in the neighborhood of the training camps. In each of these instances, these matings do not represent as much maturity of judgment as there would have been in times of peace, and hence give a less desirable sexual selection.

In considering the belligerent nation at home, the number of marriageable males is of course far less than at ordinary times. It becomes important, then, to compare the quality of the noncombatants and those combatants which survive and return home, since their absence during the war period of course decreases their reproduction as compared with the non-combatants. The marked excess of women over men, both during the war and after, necessarily intensifies the selection of women and proportionately reduces that of men, since relatively fewer men will remain unmated. This excess of women is found in all classes. Among superiors there are, in addition, some women who never marry from the lack of sufficiently eligible suitors caused by the war.

In the past, and still among many savage peoples, inter-group selection has been affected by the stealing of women from the vanquished. The effect of this has been very different, depending on whether these women would otherwise have been killed or spared, and also depending on the relative quality of their nation to that of their conquerors.

Tosum up, we find there are so many features of natural selection, each of which must be separately weighed and the whole then balanced, that it is a matter of extensive inquiry to determine whether a certain war has a preponderance of eugenic or dysgenic results. In the present war it would seem that the high quality of both sides compared with the rest of the world is so predominant a dysgenic factor that, together with the other dysgenic features, the eugenic results are overbalanced. The human species therefore on account of this is at present declining in inherent quality faster than in any previous similar length of time.

\section{Pure Lines in Cotton}

The influence of environment upon pure lines is being studied in a systematic way by the North Carolina and Mississippi Experiment Stations, which are growing the same strain of cotton in the two localities, and carefully comparing the plants at different stages. The North Carolina Station is further making a study of inheritance and association of some of the important characters of the cotton plant. A study of the value of kernels of corn taken from different portions of the ear has been made and it has been found that those from about the middle produce stalks that yield most heavily. 